\section{Referrals for cataract surgery: variations between different geographic areas within a Welsh Health Authority}

\begin{abstract}
Aim The aim of the study was to identify variations in cataract presentation within three different eye units in a single health authority and to identify any correlation between cataract presentation and social deprivation indices. We also compared our patient profile and results with the UK National Cataract Audit statistics.

Methods It was a prospective multicentre questionnaire-based project involving three hospitals: Cardiff Eye Unit-University Hospital of Wales (UHW), Royal Glamorgan Hospital - Llantrisant (RGH), and Prince Charles Hospital-Merthyr Tydfil (PCH). Demographic, clinical, and socioeconomic data were collected in patients undergoing cataract surgery. Patients were also asked to fill in the questionnaire based on the BerthPetersen Visual Function Index (VF-14) indicating difficulty in performing daily living activities.
\end{abstract}

Results A total of 112 patients were recruited in the study. Demographics were similar to National Cataract Audit. However, the percentage of patients with poor visual acuity (less than 6/60) at the time of surgery was greater at all the three hospitals compared to the national statistics. Among the three hospitals at South Wales, PCH had the lowest visual acuity in both listed and fellow eye and the lowest VF-index. Both the outpatient and surgery waiting times were longest at $\mathrm{PCH}$. The population at $\mathrm{PCH}$ also visited their optician least frequently.

Conclusion Our results show significant variation in cataract presentation between the three eye units within a single Health Authority. These variations correlate well with social deprivation indices and poor use of
R Goyal ${ }^{1,2}$, J Shankar ${ }^{1,2}$ and S Sullivan ${ }^{2}$

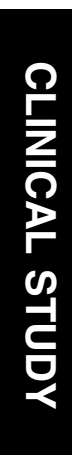

Optometric services. Local policies are needed to redress these inequalities and raise public and professional awareness of causes of poor sight in the elderly population.

Eye (2004) 18, 773-777. doi:10.1038/sj.eye.6700724

Published online 9 January 2004

Keywords: cataract; variations; optometry; social deprivation

\section{Introduction}

Cataract extraction is the most frequently performed surgical procedure in ophthalmic care. There have been several studies in the past, which have shown variation in the indication for cataract surgery. These variations have been seen both between one country and another, ${ }^{1,2}$ and between different geographic regions within the same country. ${ }^{3}$ These variations have been attributed to multiple factors including age and sex of patients, concentration of optometrists, variations in surgical practice, and variations in administrative practices of health regulatory bodies.

The aim of this study was (a) to collect demographic, clinical, and social data of patients undergoing cataract surgery in three eye units within a single health authority; (b) to identify any variations in cataract presentations between the three units; (c) to compare patient profile with the UK National Cataract Audit statistics; (d) to identify any correlation between cataract presentation and social deprivation indices.

Material and methods

The study was designed as a prospective multicentre questionnaire-based project.
${ }^{1}$ Department of Ophthalmology University Hospital of Wales 4XW, UK

${ }^{2}$ Department of Ophthalmology Royal Glamorgan Hospital Llantrisant South Wales CF72 8XR, UK 55, Maes y coed Road Heath Cardiff CF14 4HD UK

Tel: + 4402920747747

E-mail: sumitgoyal@

lineone.net

Received: 30 March 2003 Accepted in revised form: 26 August 2003

Published online: 9 January 2004 Heath Park Cardiff CF14

Correspondence: R Goyal 
Consecutive patients presenting to cataract preassessment clinic over a 2-month period (Jan-Feb 2000) were included in the study. The centres included were Cardiff Eye Unit-University Hospital of Wales, Royal Glamorgan Hospital-Llantrisant, and Prince Charles Hospital-Merthyr Tydfil. Ethical approval was obtained from the Local Research Ethics Committee. The inclusion and exclusion criteria are listed in Table 1.All patients fulfilling the inclusion criteria were invited to fill in a questionnaire. Written informed consent was obtained. Data were collected according to a predetermined set of evaluation forms. Visual acuity was recorded as distance Snellen visual acuity with correction. The Snellen acuity was then converted to the Bailey-Lovie logMAR scale for the purposes of statistical analysis. ${ }^{4,5}$ Other data that were collected are shown in Table 2.The doctor at the preassessment clinic helped the patient fill in the questionnaire based on the BerthPetersen Visual Function Index (VF-14). ${ }^{6}$ Patients were asked if they had experienced any difficulty performing 14 specific vision-dependent daily living activities when performed with appropriate spectacle correction. If yes, they were asked to indicate the amount of difficulty ranging from ' 4 ' for 'no difficulty' to ' 0 ' for 'unable to do'. The total score was divided by 14 to determine the mean score and then multiplied by 25 to give the VF-14 index score. The VF-14 Index score could range from ' 0 ' indicating inability to perform any task for which vision is required to ' 100 ' indicating no difficulty in performing any of the said tasks. The questionnaire did not reveal the identity of the patient.The SPSS software was used for data analysis. A difference of 0.1 on $\log$ MAR visual

Table 1 Inclusion and exclusion criteria

\begin{tabular}{ll}
\hline Inclusion criteria & Exclusion criteria \\
\hline Age $>50$ years & Any previous surgery on first eye \\
Senile cataract & Combined procedure \\
First eye & Traumatic or inflammatory cataract \\
Patient able to consent & \\
\hline
\end{tabular}

Table 2 Additional data collected

Age

Sex

Ocular comorbidity

ARMD, glaucoma, diabetic retinopathy, amblyopia, corneal opacity/decompensation, others

Systemic comorbidity

Diabetes mellitus, hypertension, ischaemic heart disease, COAD, stroke, arthritis, others

Waiting time for outpatients appointment

Waiting time for surgery

Frequency of optometrist visit

Social deprivation statistics acuity or 5 on the VF - 14 Index was considered to be significant. It was determined that to detect a difference in 0.1 on $\log$ MAR visual acuity with $95 \%$ power, the sample size had to be 30 .

\section{Results}

A total of 112 eligible patients were recruited into the study. These consisted of 45 patients from University Hospital of Wales-Cardiff (UHW), 36 from Royal Glamorgan Hospital, Llantrisant (RGH), and 31 from Prince Charles Hospital, Merthyr Tydfil (PCH).

Figure 1 illustrates patient demographics that are similar to National Cataract Audit figures. Ocular and systemic comorbidity was also similar between the South Wales and national population (Figure 2). Tables 3 and 4 show the mean visual acuity in operated and fellow eye at the time of listing with and without ocular comorbidity. There was no significant difference between the three centres. Table 5 shows the percentage of patients presenting with visual acuity less than 6/60 and better than $6 / 12$ in three eye units compared with the national data. The visual function index was similar in three centres (Table 6). Table 7 shows that waiting time in one of the centres was significantly longer than the other two. The number of visits to the community optician was graded into $1=$ never visited, $2=>$ once in 2 years, $3=$ every 2 years, $4=$ yearly, and $5=<$ yearly. The mean scores were $3.0 \pm 1.2$ at $\mathrm{UHW}, 2.7 \pm 1.2$ at RGH, and $2.6 \pm 1.3$ at $\mathrm{PCH}$.

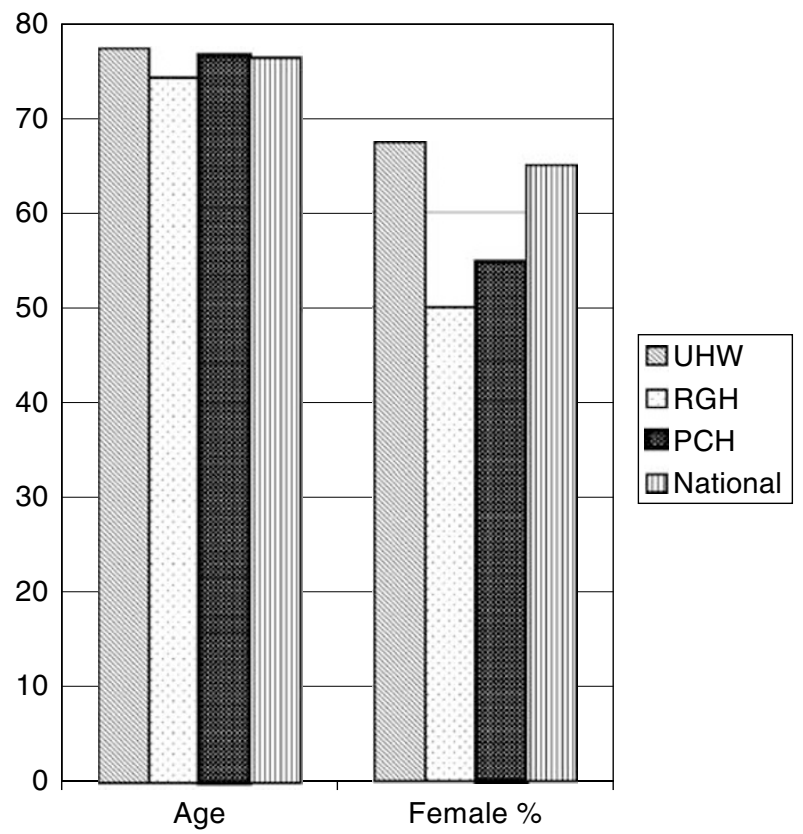

Figure 1 Age (years) and sex distribution. 


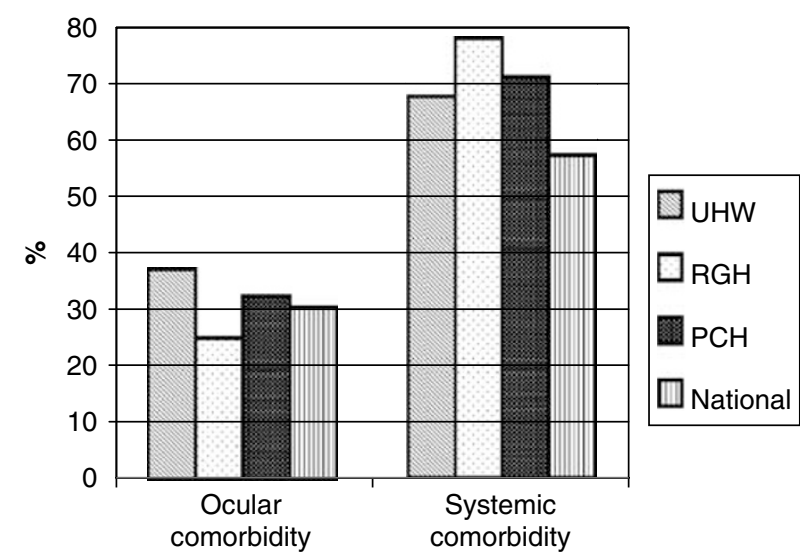

Figure 2 Ocular and Systemic Comorbidity

Table 3 Mean VA operated eye

\begin{tabular}{lccc}
\hline & $U H W$ & $R G H$ & $P C H$ \\
\hline Preop VA & $0.76(0.45)$ & $0.77(0.47)$ & $0.85(0.48)$ \\
$\begin{array}{l}\text { Preop VA (without ocular } \\
\text { comorbidity) }\end{array}$ & & & \\
\hline
\end{tabular}

Table 4 Mean VA fellow eye

\begin{tabular}{|c|c|c|c|}
\hline & UHW & $R G H$ & $\mathrm{PCH}$ \\
\hline Preop VA & $0.48(0.31)$ & $0.54(0.32)$ & $0.55(0.42)$ \\
\hline $\begin{array}{l}\text { Preop VA (without ocular } \\
\text { comorbidity) }\end{array}$ & $0.47(0.26)$ & $0.52(0.33)$ & $0.48(0.37)$ \\
\hline
\end{tabular}

Table 5 Overview of visual acuities

\begin{tabular}{lcccc}
\hline & UHW & RGH & PCH & National \\
\hline VA $<6 / 60$ & $20 \%$ & $17 \%$ & $32 \%$ & $15 \%$ \\
VA $\geq 6 / 12$ & $16 \%$ & $22 \%$ & $19 \%$ & $31 \%$ \\
\hline
\end{tabular}

Table 6 VF index

\begin{tabular}{llll}
\hline & UHW & RGH & PCH \\
\hline VFI & $72(19)$ & $66(25)$ & $66(27)$ \\
VFI without ocular comorbidity & $74(17)$ & $69(25)$ & $64(29)$ \\
VFI $>90$ & $16 \%$ & $22 \%$ & $25 \%$ \\
\hline
\end{tabular}

\section{Discussion}

The National Cataract Surgery Survey was conducted in 1990 as a prospective cross-sectional survey of National Health Service patients who had had surgery for agerelated cataract in the UK. ${ }^{3,7,8}$ Data collected included pre and postoperative clinical data, clinical outcomes,
Table 7 Waiting times (weeks)

\begin{tabular}{lccc}
\hline & $U H W$ & $R G H$ & $P C H$ \\
\hline Outpatient & 30 & 39 & 43 \\
Surgery & 30 & 24 & 38 \\
\hline
\end{tabular}

Outpatient waiting times: UHW vs PCH $(P=0.002)$, UHW vs RGH $(P=0.03)$.

Surgery waiting times: RGH $v s \mathrm{PCH}(P=0.001)$, $\mathrm{UHW}$ vs $\mathrm{PCH}(P=0.08)$.

waiting times, and the level of visual impairment at the time of first assessment, at listing, and at the time of surgery. Waiting times included both times from initial referral to listing and from listing to surgery. This study was repeated in 1997. ${ }^{9}$ However, neither of these two studies assessed the functional status of the patients. The three centres chosen for our study are representative of a University teaching hospital (UHW), a large district general hospital (RGH), and another district general hospital $(\mathrm{PCH})$ where outreach clinics and day case cataract surgery are provided by surgeons from RGH.

Patients presenting at $\mathrm{PCH}$ had a lower visual acuity in both listed and the fellow eye compared to other centres although the difference was not statistically significant. The percentage of patients with less than 6/60 vision were greater at PCH compared to the UHW, RGH, and national data. We feel that the most likely cause for this is the infrequent visit to the optician by the population of $\mathrm{PCH}$ and decreased density of optometrists in this region. The ratio of optometrist to population was $1: 7600$ in the catchment area for UHW, 1:7500 for RGH, and 1:10000 for PCH. Welsh Multiple Deprivation Index Scores (Figure 3) have indicated that the catchment area for PCH, namely Merthyr Tydfil and Cynon Valley, ranks as the most deprived area with a score of 4.00 . The area around RGH, namely Taff-Ely and Rhondda Valleys, are ranked second from bottom with a score of 16.55. The catchment area for UHW, namely Cardiff and Vale of Glamorgan, ranks 13th with a score of $60.37 . .^{10}$ This difference is of even more relevance because RGH and $\mathrm{PCH}$ are only 15 and 25 miles away, respectively, from UHW. The above statistics indicate that there is a strong correlation between provision and utilisation of Primary and Secondary ophthalmic health services and the level of social deprivation. The waiting times from listing to surgery nationally is 32 weeks. This compares favourably with UHW and RGH, but is significantly longer at PCH.

Visual acuity is a simple but important method of assessment of visual status. However, other factors like glare, contrast sensitivity, employment, ability to pursue one's profession or hobbies, general health, patients' demand linked with the surgeons own assessment of coexistent ocular conditions dictates the decision as to when to offer cataract surgery. We assessed objectively 
Least Deprived UHW University Hospital of Wales, Cardiff

RGH Royal Glamorgan Hospital, Llantrisant

Most Deprived PCH Prince Charles Hospital, Merthyr Tydfil

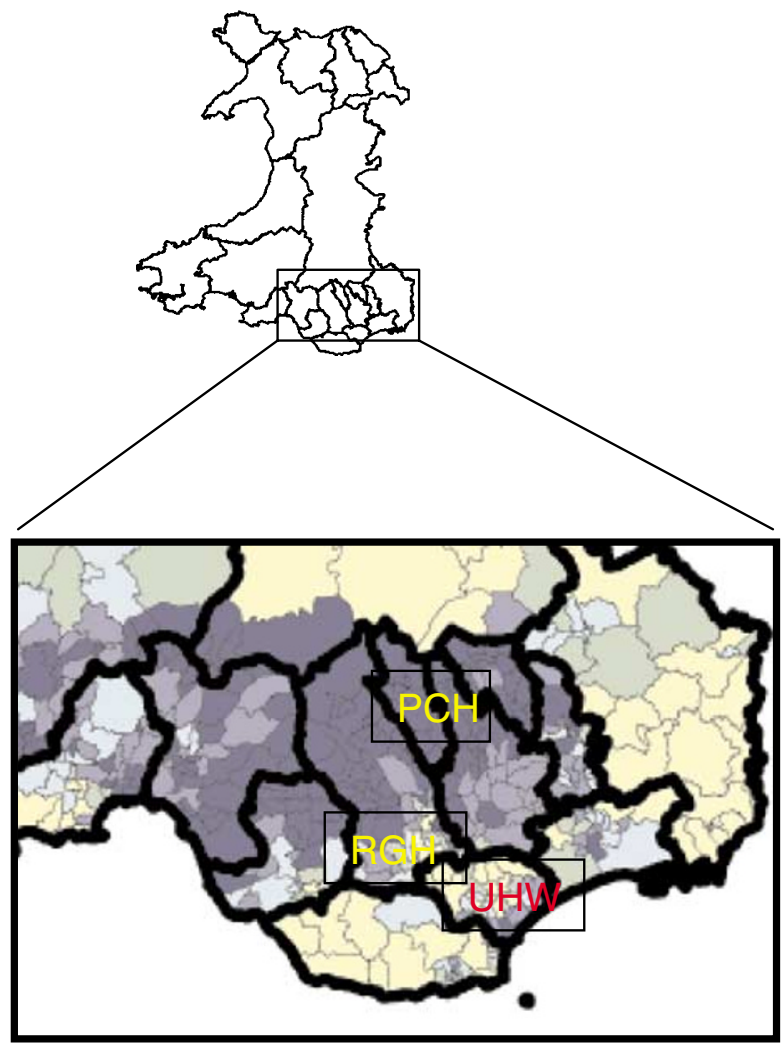

Figure 3 Welsh Index of Deprivation 2000 Health Deprivation and Disability Domain.

the functional status of our patients using the Bernthetersen VF - 14 Index. The VF14 Index has been shown to be a reliable, valid, reproducible, and internally consistent measure and has been recommended for international comparisons. ${ }^{11,12}$ The population of $\mathrm{PCH}$ had the lowest VF index in keeping with visual acuity. An interesting finding, however, was that although the visual acuity was poorest at $\mathrm{PCH}$ the percentage of patients rating the highest functional capacity (VFindex $>90$ ) was highest at PCH (Table 6). This is in keeping with the earlier findings of Stienberg et al that the visual acuity and visual function in daily life are poorly linked, and that there are other factors that determine functional capacity. ${ }^{13}$ It also indicates that functional evaluation should complement visual assessment. ${ }^{14}$ The outcome measures of cataract surgery have generally been documented in terms of improved monocular visual acuity. It would be interesting to examine the change in VF-14 Index before and following surgery in future studies.

In conclusion, our results show a significant variation in cataract presentation between the three eye units in Bro Taf Health Authority. These variations correlate well with social deprivation and poor use of Optometric services in the community. Local policies are needed to redress these inequalities. Ongoing discussions with the relevant Local Health Groups are intended to utilise this information to form an action plan to raise public and professional awareness of the causes of poor sight in older people.

An integral part of the action plan is to increase general practitioner referral rates to the Optometrist for assessment as part of the 'Extended Eye Examination' initiative launched from the 1st of May 2002 and funded by the National Assembly for Wales (http:// www.wales.nhs.uk/documents/landmark-day-foreye-care-e.htm). We hope that our results will assist the providers and purchasers of ophthalmic health care in predicting future requirements and in the allocation of resources.

\section{References}

1 Norregaard JC, Schein OD, Anderson GF, Alonso J, Dunn E, Black C et al. International variation in ophthalmologic management of patients with cataracts. Results from the International Cataract Surgery Outcomes Study. Arch Ophthalmol 1997; 115(3): 399-403.

2 Norregaard JC, Bernth-Petersen P, Alonso J, Dunn E, Black $\mathrm{C}$, Andersen TF et al. Variation in indications for cataract surgery in the United States, Denmark, Canada, and Spain: results from the International Cataract Surgery Outcomes Study. Br J Ophthalmol 1998; 82(10): 1107-1111.

3 Desai P. The National Cataract Surgery Survey: III. Process features. Eye 1993; 7(Part 5): 667-671.

4 Bailey IL, Lovie JE. New design principles for visual acuity letter charts. Am J Optom Physiol Opt 1976; 53(11): 740-745.

5 Moseley MJ, Jones HS. Visual acuity: calculating appropriate averages. Acta Ophthalmol (Copenh) 1993; 71(3): 296-300.

6 Bernth-Petersen P. Visual functioning in cataract patients. Methods of measuring and results. Acta Ophthalmol (Copenh) 1981; 59(2): 198-205.

7 Courtney P. The National Cataract Surgery Survey: I. Method and descriptive features. Eye 1992; 6(Part 5): 487-492.

8 Desai P. The National Cataract Surgery Survey: II. Clinical outcomes. Eye 1993; 7(Part 4): 489-494.

9 Desai P, Reidy A, Minassian DC. Profile of patients presenting for cataract surgery in the UK: national data collection. Br J Ophthalmol 1999; 83(8): 893-896.

10 http://www.wales.gov.uk/keypubstatisticsforwales/ content/publication/social/2001/sb13-2001/depscoresmd2000.pdf.

11 Cassard SD, Patrick DL, Damiano AM, Legro MW, Tielsch JM, Diener-West M et al. Reproducibility and 
responsiveness of the VF-14. An index of functional impairment in patients with cataracts. Arch Ophthalmol 1995; 113(12): 1508-1513.

12 Alonso J, Espallargues M, Andersen TF, Cassard SD, Dunn E, Bernth-Petersen $\mathrm{P}$ et al. International applicability of the VF-14. An index of visual function in patients with cataracts. Ophthalmology 1997; 104(5): 799-807.
13 Steinberg EP, Tielsch JM, Schein OD, Javitt JC, Sharkey P, Cassard SD et al. The VF-14. An index of functional impairment in patients with cataract. Arch Ophthalmol 1994; 112(5): 630-638.

14 Bergner M, Bobbitt RA, Carter WB, Gilson BS. The Sickness Impact Profile: development and final revision of a health status measure. Med Care 1981; 19(8): 787-805. 